\title{
Novas práticas pedagógicas: considerações sobre transformações escolares a partir da atuação de docentes do Núcleo Takinahakỹ
}

NAZARENO, Elias ${ }^{1}$

Desde o início do processo de colonização do Brasil, aproximadamente em 1532, a educação escolar indígena foi considerada como estratégica para o projeto de colonização e subalternização dos povos indígenas brasileiros. Não por acaso, essa tarefa foi delegada às ordens religiosas, sobretudo à jesuíta, pois elas detinham, além do monopólio em relação à produção do conhecimento e sua divulgação, o poder espiritual, por meio do cristianismo, e a chancela, por parte do Estado português, para que atuassem de forma uníssona com os interesses políticos, econômicos e expansionistas desse Estado. Temos, assim, dois pilares básicos em tal projeto de colonização: a educação escolar, com base nos valores ocidentais, e a cristianização ou catequização dos povos indígenas.

Desse modo, a escola indígena passou a estar presente no cotidiano dos mais diversos povos indígenas, daqueles recém-contatados e dos que viriam a sê-lo nos séculos posteriores à invasão do que hoje conhecemos como Brasil. As estratégias de subalternização passaram desde a imposição da língua portuguesa até a tentativa de apagamento dos conhecimentos indígenas e de suas formas de bem-viver.

Essa imposição - baseada na assimilação do século XVI até princípios do século XIX e na integração dos povos indígenas à sociedade nacional do século XIX em diante - ficou basicamente inalterada até o final do século XX. Na década de 1980, depois de séculos de lutas e mobilização, o Brasil foi, pela primeira vez em sua história, por meio da Constituição de 1988, finalmente considerado um País pluriétnico e plurilíngue.

Esse reconhecimento em termos legais teve como desdobramento uma série de transformações que geraram, entre outras coisas, a necessidade de adaptação da educação escolar indígena, tendo em vista as especificidades das diversas línguas indígenas existentes no Brasil - aproximadamente 200 línguas - e do reconhecimento dos conhecimentos indígenas como essenciais para sua preservação e continuidade como povos indígenas. Esse processo foi lento e tortuoso, em primeiro lugar pelo desinteresse por parte do Estado brasileiro em regulamentar, por meio de leis, essas adaptações. Somente com a implantação da Lei de Diretrizes e Bases da Educação (LDB), em 1996, a educação escolar indígena passou a contar com uma atenção diferenciada pelo Ministério da Educação e pelas Secretarias de Educação dos respectivos estados da Federação.

Professor Associado I do curso de Educação Intercultural Indígena da Universidade Federal de Goiás (UFG). Coordenador Institucional do Pibid Diversidade dessa instituição até março de 2018. 
Nesse sentido, tornou-se obrigatória a necessidade de construir uma educação diferenciada para os povos indígenas brasileiros.

Foi com base nessas necessidades e nos marcos legais oriundos da Constituição de 1988 que foram criados os cursos de Licenciatura em Educação Intercultural Indígena em algumas universidades brasileiras, sobretudo a partir de 2003. A enorme demanda reprimida em termos de formação de professores indígenas capazes de assumir a educação escolar, conforme previsto na LDB, em suas respectivas comunidades, deveria ser atendida por meio de cursos de formação que levassem em consideração sua diversidade linguística e epistemológica. Destarte, diante da complexidade intercultural de tal empreendimento pedagógico, foram necessárias estratégias de colaboração em termos interculturais entre as Instituições de Ensino Superior no Brasil e as diversas comunidades indígenas envolvidas em sua construção.

Nesse caso, algumas indagações se fizeram presentes, pois como construir uma educação escolar indígena verdadeiramente intercultural e interepistêmica após séculos de imposição de um modelo educacional logocêntrico e monológico? Quais seriam as estratégias mais adequadas para a composição de matrizes curriculares que desconstruíssem tal modelo e contemplassem os conhecimentos indígenas? Entre estas e outras indagações, talvez a mais relevante e complexa diante de tais desafios tenha sido aquela que destacava o papel reservado aos povos indígenas na construção desse empreendimento, atentando-se para a enorme diversidade em termos linguísticos e epistemológicos existente entre os mais de 315 povos indígenas no Brasil.

Tendo em vista essas indagações e demandas, em 2007, teve início o curso de Licenciatura Intercultural Indígena na Universidade Federal de Goiás (UFG). O curso, pensado e negociado entre professores da UFG e lideranças indígenas da etnorregião Araguaia-Tocantins desde o início dos anos 2000, conta hoje com 273 discentes indígenas de 23 povos, sendo eles: Apinajé, Bororo, Canela, Gavião, Guajajara, Javaé, Juruna, Kalapalo, Kamaiurá, Karajá, Krahô, Krikati, Kuikuro, Mehinako, Tapirapé, Tapuia, Terena, Timbira, Xakriabá, Xambioá, Xavante, Xerente e Waura, envolvendo os estados de Goiás, Maranhão, Mato Grosso, Tocantins e Território do Xingu. O tempo para a formação dos professores indígenas no curso é de cinco anos, divididos entre a matriz básica, que tem duração de dois anos e a matriz específica, com duração de três anos.

$\mathrm{Na}$ matriz básica, os estudantes indígenas trabalham temas contextuais2 que são, em tese, comuns a todos os povos indígenas, por exemplo, educação bilíngue intercultural, línguas indígenas, territórios indígenas etc. Nas matrizes de formação específica, que são as Ciências da Cultura, Ciências da Linguagem e Ciências da Natureza, os discentes aprofundam seus conhecimentos por meio de temas

2 "A iniciativa pioneira do uso dos temas contextuais na educação foi realizada pelos propositores do curso de Licenciatura Intercultural Indígena da Universidade Federal de Roraima (UFRR) em seu Projeto Político Pedagógico (PPP), entre os anos de 2000 e 2003. De acordo com Repetto (2012, p. 18), “[p]ropomos temas contextuais para questionar, para experimentar e pesquisar se é possível uma outra forma de estudar e de organizar o currículo. Os temas contextuais não são uma fórmula. Devem ser discutidos, adaptados, modificados e criticados. Os temas contextuais devem fazer uma leitura a partir da Interculturalidade" (PEREIRA; ARAÚJO; NAZARENO, 2018, p. 3). 
contextuais mais voltados para cada uma das matrizes citadas, como etnicidade e diversidade cultural, modalidades de ensino bilíngue, cosmos, saberes locais e universais, respectivamente.

Assim que ingressa na matriz específica tem início o estágio pedagógico supervisionado. São, ao todo, seis estágios, em que o discente deverá desenvolver suas habilidades em relação às práticas pedagógicas interculturais. Durante o estágio, o discente conta com o apoio dos Comitês Orientadores, 3 que deverão auxiliá-lo na escolha dos temas contextuais que trabalharão nas escolas indígenas. Em geral, o discente escolhe um tema contextual, como pintura corporal ou alimentação indígena, e deverá trabalhar em sala de aula com pelo menos três aulas para cada tema contextual. Assim que o tema é escolhido, ele deverá realizar uma pesquisa sobre o assunto em sua comunidade. Em geral, as fontes para a pesquisa são os anciãos e anciãs de cada povo. Cumprida essa etapa, o discente deverá montar um plano de curso para cada uma das aulas que leve em consideração a justificativa, os objetivos, a metodologia que será utilizada e os resultados esperados, bem como as considerações dos estudantes indígenas.

O estágio pedagógico tem se constituído desde o início do curso, em 2007, como um dos aspectos mais importantes em termos de construção de novas bases epistemológicas e de novas práticas pedagógicas nas escolas indígenas.

Foi com base nessas experiências que, a partir das ações do Pibid Diversidade, da UFG, na área de Ciências da Cultura, implementou-se como uma de suas iniciativas o levantamento, nas escolas indígenas, de práticas pedagógicas inovadoras e decoloniais a partir das prováveis influências que o curso de Educação Intercultural da UFG, por meio da formação dos professores indígenas, havia gerado nas escolas indígenas no estágio pedagógico e com a utilização dos temas contextuais.

A proposta teve como objetivo fundamental identificar e refletir sobre práticas pedagógicas da escola indígena, especialmente aquelas constituídas a partir dos princípios do curso e da trajetória acadêmica dos/das professores/professoras indígenas. (NAZARENO, 2017, p. 504).

Essa ação resultou na publicação do livro Novas práticas pedagógicas: considerações sobre transformações escolares a partir da atuação de docentes do Núcleo Takinahakỹ, organizado pelo professor Alexandre Ferraz Herbetta, um dos coordenadores da área de Ciências da Cultura do Pibid Diversidade e professor do curso de Educação Intercultural da UFG. Desde a colação de grau da primeira turma do curso, que ingressou em 2007, e nas demais turmas subsequentes, os discentes elaboram, na última etapa do estágio pedagógico, um texto que deve contemplar suas experiências no estágio, relatando os êxitos e as dificuldades encontrados a

3 No curso de Educação Intercultural da UFG cada povo indígena, à exceção dos povos do Xingu, conta com a presença de um Comitê Orientador, composto por um ou mais professores do curso e pelos discentes daquele povo. O trabalho de orientação é realizado durante as etapas presenciais na UFG (janeiro, fevereiro, julho e agosto) e nas aldeias (abril, maio, outubro e novembro). 
partir da utilização das novas práticas pedagógicas. Tais práticas estão baseadas, sobretudo, nos princípios da interculturalidade crítica e da transdisciplinaridade e os textos elaborados por parte dos discentes do curso são em grande parte utilizados no livro.

Essa obra que está dividida em sete capítulos, retrata parte dessas experiências vivenciadas nas escolas indígenas pelos povos Karajá, Krahô, Apinajé, Xerente, Tapirapé, Gavião-Timbira, Javaé e Krikati. Em cada um dos capítulos os docentes indígenas apresentam, a partir da realidade de cada povo, suas análises acerca das novas práticas pedagógicas adotadas em sala de aula. Como afirma o organizador do livro, Alexandre Herbetta, a obra tem como objetivo fundamental apresentar as experiências transcritas pelos intelectuais indígenas que revelam as transformações que vêm ocorrendo nas escolas indígenas e em suas respectivas comunidades a partir da adoção de novas práticas pedagógicas. Estas revelam-se como poderoso mecanismo de envolvimento das comunidades indígenas com suas escolas na transformação dialógica dos conteúdos adotados por meio do fortalecimento dos conhecimentos indígenas, que passam a compor a matriz curricular das escolas indígenas e os Projetos Políticos Pedagógicos das escolas indígenas.

Note-se que, segundo Herbetta, um dos pontos-chave que surge por meio das experiências apresentadas é justamente a problematização do regime disciplinar, incompatível com a possibilidade de uma abordagem interepistêmica que considere outras formas de conhecer, ali representadas pelos temas contextuais.

Os temas contextuais permitem, de acordo com os relatos apresentados no livro, esparramar, esticar o conhecimento e não contê-lo em compartimentos fechados, como são e querem as disciplinas. Além disso, estão carregados de conhecimentos pertinentes, entendidos como conhecimentos que estão vivos e fazem parte do cotidiano das comunidades indígenas.

As novas práticas pedagógicas possibilitam, como já dito, a aproximação e o envolvimento das comunidades indígenas com a escola, seja por intermédio das palestras de anciãos e anciãs, das oficinas realizadas para tratar de temas contextuais como, alimentação tradicional, medicina indígena, pintura corporal, lixo nas aldeias etc., seja pela superação das cercas ou muros das escolas e de sua temporalidade ocidental ou por meio das aulas dadas em temas contextuais, como pesca e caça tradicionais, lagos e rios, plantas medicinais etc. Na utilização de todos esses temas contextuais torna-se patente a incompatibilidade entre o modelo disciplinar imposto pela colonização - preso a lógicas utilitaristas fortemente delimitadas por uma noção de temporalidade atada ao calendário escolar e a cargas horárias rigidamente definidas - e os conhecimentos indígenas, inseparáveis da natureza e do falso dualismo entre teoria e prática.

O livro Novas práticas pedagógicas, além de constituir-se em um importante recurso didático e metodológico para aqueles que trabalham com a educação escolar indígena é, igualmente, um importante documento acerca das possibilidades de desconstrução da colonialidade do saber imposta por séculos de colonização aos povos indígenas e à sociedade brasileira como um todo. 


\section{Referências}

HERBETTA, Alexandre Ferraz. Novas práticas pedagógicas: considerações sobre transformações escolares a partir da atuação de docentes do Núcleo Takinahakỹ. 1. ed. Goiânia: Imprensa Universitária, 2018.

BRASIL. Constituição (1988). Constituição da República Federativa do Brasil. Brasília, DF: Senado, 1988.

Senado Federal. Lei de Diretrizes e Bases da Educação Nacional: no 9394/96. Brasília: Senado Federal, 1996.

HERBETTA, Alexandre Ferraz (Org.). Novas práticas pedagógicas: considerações sobre transformações escolares a partir da atuação de docentes do Núcleo Takinahakỹ. 1. ed. Goiânia: Imprensa Universitária, 2018.

NAZARENO, Elias. Pibid-diversidade: construção de bases epistemológicas na formação de professores indígenas (Pibid-diversity: construction of epistemological bases in the formation of indigenous teachers). Crítica Educativa, v. 3, p. 493-506, 2017.

REPETTO, M. Os Sentidos das Fronteiras na Transdisciplinaridade e na Interculturalidade. Textos\&Debates, Boa Vista, n. 22, p. 13-30, jul./dez. 2012. 